Academy for that date was in R.A. $308^{\circ} 25^{\prime}$, Decl. $-24^{\circ} 17^{\prime}$. Pingré in his Cometographie mentions that according to Struyck this position is erroneous, and that ten rrinutes should be added to the declination and five to the right ascension as printed in the Mémoires, adding that if Lacaille has used the Bologna observation his orbit would be less accurate than that of Struyck. The Bologna observers Manfredi and Stancari found the comet on November 25, in the same field of view of an 8.foot telescope, with two stars, the distance between which they estimated at $\mathrm{o}^{\prime}$. At $7 \mathrm{~h}$. $14 \mathrm{~m}$. $47 \mathrm{~s}$. apparent time the centre of the comet was in the right line joining these stars, and its distance from the northernmost star was one-third of the distance between them. It is easy to see from the rough position given, that the stars in question are Piazzi XX., 296 and 298, and carrying back his places, we have for the position of the comet referred to the mean equinox of $1708^{\circ} \circ$, R. A. $307^{\circ} 49^{\prime} \cdot 3$, Decl. $-23^{\circ} 44^{\prime} \mathrm{I}$. The equation of time was $12 \mathrm{~m}$. $37 \mathrm{~s}$. subtractive from apparent time, and hence the Greenwich mean time of observation was November $25^{\cdot} 26163$. The place calculated from Lacaille's orbit, first published in his "Leçons d'Astronomie," differs $+7^{\prime} \cdot 2$ in R.A. and $+5^{\prime} \cdot 6$ in Decl., so that it is evident he did not use the position as erroneously deduced in the Mémoires. The agreement of his elements with the Paris observation on December I 7 is fairly good; there is a much larger deviation from the approximate places determined at Bologna, on January 13 and 17 ; but these observations of Manfredi and Stancari are probably affected with very material errors, as such is certainly the case with the deduced position for the night of discovery. So far as can be judged from this partial comparison of Lacaille's elements with observation, the hypothesis of identity of the comet of 1707 with that of 1846 is not supported, but the observations of the former may deserve further discussion.

The Transit of Venus.-Prof. C. A. Young has published his observations of all four contacts in the late transit of Venus, made at the Halsted Observatory, Princeton, N.J., with the 23-inch equatorial, and a power of 160 . At the two internal contacts the aperture was diminished to $5 \frac{3}{4}$ inches, "in order to make the observations comparable as far as possible with those of the various government expeditions," but at the external contacts the full aperture was employed; a polarising helioscope was attached. We have compared the times given by Prof Young with those calculated from the reduction equations published in this column, in the formation of which it was the main object to get geometrical contacts. It has been previously mentioned that there was a close agreement between prediction and observation in the case of the results obtained at Harvard College, and the following are the small cifferences (calc.-obs.) for Prof. Young's :-

$$
\text { I. }-16 \mathrm{~s} \text {. } \ldots \text { II. }+3 \mathrm{~s} \text {. } \ldots \text { III. }-\mathrm{r}_{5} \mathrm{~s} . \quad \ldots \quad \text { IV. }-4 \mathrm{~s} \text {. }
$$

The British Association Catalogue of Stars.-We lately remarked, not without some surprise, that a copy of this work was priced in a continental list of second-hand books at the high figure of $12 l$. IOs., or about three times the cost at its publication in 1845 . Such a fact naturally induces the query, Is there occasion for a new general catalogue of the principal fixed stars, or, say, of stars within the limit of naked-eye vision? It is a question upon which there will probably be a wide difference of opinion, and it is one that it would be of interest to discuss.

\section{GEOGRAPHICAL NOT'ES}

THE last number of the Verhandlungen der Gesellschaft für Erdkunde of Berlin contains a paper by Prof. Brauns, late of Japan, on the Island of Yezo. The writer agrees with $\mathrm{Mr}$. Keane and other ethnologists that the Ainos are a totally different race from the Japanese. The number of these people in Yezo and the Kuriles is given by the Japanese Government as I8,00o, but many authors place the number as high as 50,000 . In Saghalin there are 10,000 to 12,000 , and if those in the southern part of Kamschatka who are living under Rus-ian rule are included, the total number of the race would probably be from 60,000 to 70,000 . In the same issue the indefatigable explorer of the Philippines, Herr Jagor, describes briefly a recent journey through Luzon. An interesting communication also is a list of the papers published by the Geograpbical Society of Tokio in its volume for 1880 . This Society is composed, we believe, alwost wholly of natives, and its papers are printed in
Japanese. There appear to have been in all thirty-eight com. munications of one kind or another; the writers or translators (for some of the papers are apparently tran-lations from others in European languages) are in all cases Japanese. Among the papers are several on the history and geography of Okinawa, as the Japanese call the Loochoo group; the climate of Peking; Japane e intercourse with foreign countries in the middle ages; a journey to Vladivostock; the history of geography in Japan; history and geography of Persia by a Japanese who had travelled through the country; description of Autralia; descrip. tion of a voyage in the Persian Gulf; of a journey on the Khirgiz steppes; ancient Japanese geographical names; description of Saghalin ; on the absence of precious stones in Japan, \&c., \&c. Some of these papers would hardly meet:with a favourable reception from the Council of the Royal Geographical Society; but in Japan they are listened to and read afterwards in their printed form by hundreds of people who have never left their own country, and who possess but a very small geographical literature. When this is remembered, the list will appear not only a creditable one to the travellers, but also a most useful one for the spread of geographical knowledge in Japan, which after all is the purpose of the Society.

THE annual report of $\mathrm{Mr}$. Tremlett, the British Consul at Saigon, contains some interesting geographical information about the northern and less known districts of the Indo-Chinese reninsula. The governor of Cochin China sent out an expedition to explore the country between the Meikong and Annam at about $14^{\circ}$ latitude. The party left Peamchileng, on the Meikong, proceeding eastward. After passing the river valley the country became hilly and wooded, intersected with numerous watercourses. No difficulty was experienced until the arrival of the travellers near the Cambodian frontiers. As they proceeded the hostility of the people became yet more pronounced, and finally their passage towards Annam was closed altogether. They were finally compelled to retreat, losing all their baggage on the way, and after three months' absence they reached a friendly post. The Mois inhabit the wilds between Cambodia, Siam, Burmab, and China. Commerce, properly speaking, does not exist among them, and traffic is carried on by exchanges. The various roads and river are stopped up by the people themselves to prevent the passage of pillagers and enemies; as a result the people are very backward. Money is almost unknown or unappreciated among them. A native who will not work for a dollar a day will do so for a bell costing a few cents. The articles most valued by the Moïs are buffaloes, red and white cottonades, glass ware, brass wire, utensils, salt, and salt fish.

From the same report we learn that an exploration of the upper waters of the Saigon river by Lieut. Gautbier shows that previous charts are incorrect; the names given in them being imaginary. There appears to have existed in this region in former times one or more states in an advanced stage of civilisation, as may be seen by ruins still remaining, probably offshoots of the famous Angker Wat. The present race of Moïs claim no descent from their predecessors on the soil, and indeed it would be difficult to find a lower state than theirs. It is difficult to communicate with them, as the language is not easily picked up by the Annamites. They appear to be in a state of independence, paying no tribute to any of their neighbours, although the King of Cambodia is their nominal suzerain. The report concludes by saying that the French Government will have to send a much more serious expedition if anything is to be learned about these regions; two or three men can learn nothing.

THE great attention which France has given for many years past to the Indo-Chinese peninsula is shown by a return printed in the Proceedings of the Societé Académique Indo-Chinoise of all the scientific expeditions despatched by the French Government to this region. These embrace archæological, ethnological, geographical, and other scientific objects, and up to I $88 \mathrm{I}$ they were seventy seven in number. They commence as far back as r68o, when the Jesuit Pallu visited the courts of Tonkin and Annam. Seventeen of these took place before the military occupation of any part of $\mathrm{C}$ chin China by the French; thirty. three were sent by the Ministry of Public Instruction, chiefly for archæological purposes, while the remaining twenty-seven were sent by the Ministry of Marine and the Colonies, and were devoted principally to exploration. To understand the mass of scientific work done by the French in Indo-China, it must be remembered that these seventy-seven expeditions do not include the innumerable journeys and researches of the missionaries, 
which commence as far back as the end of the fifteenth century, the various expeditions sent out by private enterprise, those despatched for military, naval, or diplomatic purposes, or, finally, the various hydrographic or geodetic surveys undertaken by the French authorities in Cochin China.

THE teachers at the school for the sons of Japanese nobles in Tokio appear to have hit upon a notable method of teaching physical geography. In the court behind the school building is a physical map of the country, between three and four hundred feet long. It is made of turf and rock, and is bordered with pebbles, which look at a little distance much like water. Every inlet, river, and mountain is reproduced in this model with a fidelity to detail which is wonderful. Latitude and longitude are indicated by telegraph wire:, and tablets show the position of the cities. Ingenious devices are employed in illustrating botanical studies also. For example, the pine is illustrated by a picture showing the cone, leaf, and dissected flower, set in a frame which shows the bark and longitudinal and transverse sections of the wood.

IN No. IO3 of the Zeitschaft of the Berlin Geographical Society will be found a fine series of new large scale maps by $\mathrm{H}$. Kiepert on the region containing the ruins of Babylon, embodying the results of new surveys and explorations. In the same number Herr Karl Schneider has a long paper on the valley formations of the Eifel.

Prof. FrIES has written an interesting paper proposing that part of Greenland should be colonised by Lapps. He maintains that the country would be a paradise to the mountain Lapps, that it is no more inhospitable than their own country, that there would be no restrictions to their wanderings, and that in the interior in summer and on the coast in winter they would find abundant forage for their herds. Prof. Fries is of Nordenskjöld's opinion, that in the interior abundant reindeer pasture will be found. Moreover, as a Lapp cm always follow where a reindeer leads, this would be an excellent plan of discovering the true nature of the interior; it seems certainly worth trying.

Two gentlemen from Münster (Westphalia)-Dr. Bachmann and Dr. Friedrich Wilms - are about to start on a scientific tour to Southern Africa, the Transvaal to begin with, in order to make zoological and botanical researches. Their journey will extend over several years, and the travellers will endeavour to establish direct commercial relations between the South African colonies and Germany.

\section{ELECTRICAL UNITS OF MEASUREMENT ${ }^{1}$}

$T H E$ lecturer began by observing that no real advance could be made in any branch of physical science until practical methods for a numerical reckoniny of phenomena were established. The "scale of hardness" for stones and metals used by mineralogists and engineers was alluded to as a mere test in order of merit in respect to a little understood quality, regarding which no scientific principle constituting a foundation for definite measurement had been discovered. Indeed it must be confessed that the science of strength of materials, so all important in engineering, is but little advanced, and the part of it relating to the quality known as hardness least of all.

In the last century Cavendish and Coulomb made the first advances towards a system of measurement in electrical science, and rapid progress towards a complete foundation of the system was effected by Ampère, Poisson, Greən, Gauss, and others. As late as ten years ago, however, regular and systematic measurement in electrical science was almost unknown in the chief physical laboratories of the world; although as early as I 858 a practical beginning of systematic electric measurement had been introduced in the testing of submariue telegraph cables.

A few years have sufficed to change all this, and at this time electric measurements are of daily occurrence, $n$ t in ou" scientific laboratorie: only, but also in our workshops and factories where is carried on the manufacture of electric and telegraphic apparatus. Thus ohms, volts, amperes, coulombs, and microfarads are now common terms, and measurements in these units are commonly practised to within one per cent. of accuracy. It seems, indeed, as if the commercial requirements of the application of electricity to lighting and other $u$ ses of everyday life I Abstract of lecture on "Electrical Units of Measurement," by $\mathrm{Sir}$ William Thom F.R.SS.L and E., M.Inst.C. E. delivered on Thurs day evening, May $3,188_{3}$, at the Institution of Civil Engineers. were destined to influence the higher region of scientific investigation with a second impulse, not less important than that given thirty years ago by the requirements of submarine telegraphy.

A first step toward the numerical reckoning of properties of matter is the discovery of a continuously varying action of some kind, and the means of observing and measuring it in terms of some arbitrary unit or scale division; while the second step is neces:arily that of fixing on something absolutely definite as the unit of reckoning.

A short historical sketch was given of the development of scientific measurement, as applied to electricity and magnetism, from its beginning with Cavendish about 100 years ago, to the adoption of the absolute system of measurement by this country in I869, at the instance of the British Association Committee on Electric Standards. The importance in this development of the originating works of Gauss and Weber was pointed out, as also of the eight years' labours of the British Association Committee. This Committee not only fairly launched the absolute system for general use, but also effected arrangements for the supply of standards for resistance coils, in terms of a unit, to be as nearly as poisible $10^{9}$ centimetres per second. This unit afterwards received the name of the ohm, which was adopted from a highly suggestive paper which had been communicated to the British Association in 186I by Mr. Latimer Clark and Sir Charles Bright, in which some very valuable scientific methods and principles of electric measurement were given, and a system of nomenclature-ohmas, kilohmas, farads, kilofarads, volts, and kilovolts - now univer:ally adopted with only unessential modification, was proposed for a complete system of interdependent electric units of measurement. At the International Conference for the Determination of Electrical Units held at Paris in $1 \delta 82$, the absolute system was accepted by France, Germany, and the other European countries; and Clark and Bright's nomenclature was adopted in principle and extended.

Gauss's principle of absolute measurement for magnetism and electricity is merely an extension of the astronomer's method of reckoning mass in terms of what may be called the universal gravitation unit of matter, and the reckoning of force, according to which the unit of force is that force which, acting on unit of mass for unit of time, generates a velocity equal to the unit of velocity. The universal-gravitation unit of mass is such a quantity of matter, that if two quantities, each equal to it, be placed at unit distance apart, the force between them is unity.

Here mass is defined in terms of force and space, and in the preceding definition force was defined in terms of mass, space, and time. Eliminating mass between the two, it will be found that any given force is numerically equal to the fourth power of the velocity with which any mass whatever must revolve round an equal mass, fixed at such a distance from it as to attract it with a force equal to the given force. And, eliminating force between the two primitive definitions of the universal gravitation system, it will be found that any given mas; is numerically equal to the square of the velocity with which a free particle must move to revolve round it in a circle of any radius, multiplied by this radius. Thus, take a centimetre as the unit of length, and a mean solar second as the unit of time, and adopt $5^{\circ} 67$ grammes per cubic centimetre as the mean density of the earth from Baily's repetition of Cavendish's experiment, and suppose the length of tha seconds' pendulum to be 100 centimetres, and neglect the oblateness of the earth and the centrifugal force of its rotation (being at the equator only $\mathbf{I} / 289$ of gravity), the resulc for the universal gravitation units of mass and force is respectively $15.3^{6}$ French tons, and $15^{\prime} 3^{6}$ megadynes, or $15^{\circ} \circ 7_{\text {times }}$ the terrestrial surface-weight of a kilogram.

The ultimate principles of scientific measurement were illustrated by the ideal case of a traveller through the universe who has brought with him on his tour no weights, no measures, no watch or chronometer, nor any standard vibrator or spring balance, but merely Everett's units and constants, and a complete memory and understanding of its contents, and who de-ires to make for himself a metrical system agreeing with that which he left behind him on the earth. To rec vver his centimetre the readiest and most accurate way is to find how many wavelengths of sodium light there are in the distance from bar to bar of a grating which he can engrave for himself on a piece of glass. How easily this is done, suppoing the grating once made, was illustrated by a rajid experiment performed in the course of the lecture, without other apparatus than a little piece of glass with 250 fine parallel lines engraved on it by a diamond, and two candles and a measuring tape of unknown divisions of 